\title{
INDEXICALITY AND SPECTATORSHIP IN DIGITAL MEDIA: WAKING LIFE AS HYBRID DIGITAL ARTIFACT
}

\section{Erik Marshall}

Wayne State University

\section{Abstract}

This essay explores changes in concepts of realism and spectatorship in the digital age. With digital technology, images no longer bear witness to reality in the same way envisioned by theorists such as Andre Bazin, and a new model of spectatorship must follow this loss of indexicality. The digital rotoscoping technique employed in Richard Linklater's / Waking Life/demonstrates this split between reality and image, in part by preserving the real beneath an entirely created artistic surface.

Keywords: digital; realism; spectatorship.

Spectatorship in the time of digital media is dramatically different from that of the classical film period, and even from that of the more recent television era. The ways in which spectators perceive, observe and understand images have changed in the last two decades, due to several different phenomena: the loss or change of indexicality that attends digital imagery; the proliferation of viewing and distribution devices, including different types of screens, delivery mechanisms such as DVD's and telecommunications; and the popularity of increasingly

\begin{tabular}{|l|l|l|l|l|}
\hline Ilha do Desterro & Florianópolis & no 51 & p. 301-316 & jul./dez. 2006 \\
\hline
\end{tabular}


realistic video games. These changes have affected spectatorship and film aesthetics in many interrelated ways. Films as diverse as Fight Club, The Matrix, Memento, Dark City, Strange Days, and even The Truman Show bear traces of the effect digital media have had on film. This essay will examine the film Waking Life as an example of film that works across most of the registers of digital media, complicating traditional notions of realism and the relationship between spectator and film.

Many theorists of the digital technology have noticed the shift from recorded to created images that digital technology brings. Lev Manovich, in his 1995 "What is Digital Cinema?", asserts that movingimage technologies, of which photographic film is but one, derive from a design background that shares as much with painting as photography, and that digital media returns film to these roots. For him, animation was the original function of cinema, which was then taken over by photography, and now has the chance to return to its original vocation. Stephen Prince attempts to resolve the issue by introducing a correspondence-based model of realism that relies on interaction between the spectator and the moving image, as opposed to relationship between the image and the profilmic event. He demonstrates that digital imaging can produce a "perceptual realism," where the image corresponds with the ways in which viewers experience threedimensional space. The more an image, whether photographically or digitally produced, acts in accordance with generally agreed-upon behaviors of objects in space, the more it can be said to be perceptually real. Taken further, digital realism refers to the phenomenon of objects appearing to behave and interact with other objects, virtual or real, in ways that are consistent in the universe posited in the film. This model of digital imaging technologies posits a new type of spectatorship: "Digital imaging alters our sense of the necessary relationship involving both the camera and the profilmic event" (124, italics in original). This altered sense results in a relationship between spectator and film that rests on "the application of internally valid perceptual correspondences with the 3D world," which establish the credibility of 
the digital image, and "establish bridges between what can be seen and photographed and that which can be 'photographed' but not seen" (124). This last statement preserves a sense of photography without relying on the indexical, or even on the independent existence of the photographed object, shifting the criteria from realism to the phenomenological perception of the spectator.

For some, the indexicality of the image leads to a privileging of particular types of filming, and to aesthetic prescriptions for realism. The connection between indexicality and realism is important when considering the status of the image throughout the twentieth century, and its relation to realistic fiction. Andre Bazin is perhaps one of the most famous champions of a realism that attempts to exploit the inherent indexicality of the image. For Bazin, indexicality is the most salient characteristic of the photographic image, and his endorsement of particular styles of realism reveals this emphasis. Bazin's comparison of photography to mummification, or the death mask, usefully illustrates the notion of the camera as a passive recorder of visual reality, as the light coming through the lens actually touches the film, forever preserving the reality of the moment. Privileging this indexical connection between the photographic image and that which it represents, Bazin goes on to champion a realist style, characterized in part by aesthetic choices, such as long takes and deep focus. Kracauer, as different as his ideas are from Bazin's, also recommends various techniques for discovering physical reality within film. And much of film history involves more or less straightforward representations of objective realities, even within fictional films. The by-product of the implicit understanding of film as indexical is the belief in the reality of what is projected on the screen, and a desire for conventions and techniques that reinforce this belief.

The function of indexicality in the understanding of spectatorship also deserves attention. While a realist style encourages an interpretation of events as real, much of the work happens within the spectator. For many decades, the primary viewing position for moving images was in a dark theater, in public, with a large screen in front and a projector in 
the rear. Television changes this a bit, although the content of television historically has been different from that of the cinema. Until the advent of the VCR in the 70s, the only place to see uninterrupted feature-length films was in the theater, so film scholars were safe in assuming a particular type of viewing situation. This situation is important in helping to determine the type of reaction a spectator might have to a series of moving images.

Televisual and theatrical images still share indexicality through much of the $20^{\text {th }}$ century, even if their immediacy and viewing context change. Realistic conventions in film change through the decades as television exerts force economically and stylistically, but the assumption remains that the images themselves, no matter how staged, have a cause-effect relationship with that which they represent.

While some theories of realism rely heavily on how images are presented (the long take, the close-up, etc.), the spectator is often left out of the equation. Likewise, many spectator theories posit a universal, passive viewer that comprehends the image in a predictable and uniform way. Both fields of study rely on an understanding of moving images as indexical and the viewer as passive in front of a screen.

In the late $20^{\text {th }}$ century, however, digital technology has changed both of these situations. $21^{\text {st }}$ century viewers no longer assume that a moving image is an indexical sign pointing to the reality depicted within it, and they are far less passive than their predecessors, or at least more active in making meaning than previously thought. The proliferation of various screen technologies and more interactive moving image technologies affects the way in which we interact with images, even those that seem traditionally created and exhibited.

Asbjoern Groenstad reacts to this phenomenological approach by asserting that photographic and digital imagery are ontologically distinct, and that the latter abandons film's ontological project of preservation, as elaborated by theorists like Bazin. For Groenstad, the materiality of film is important, and digital imagery constitutes a forgery. He claims that audiences are "...twice duped. Not only is the world on the screen-which the viewer processes as perceptually 'real'—not 
constituted by particles of actual reality, it is not even composed of chemicals and light but of a chain of computerized algorithms" (18). In this case, he argues, digital technology achieves not a perceptual realism, but a "hyperrealism (in Baudrillard's sense) in relation to what for a lack of a better term could be referred to as post-cinema" (18). Like Manovich, he proposes that digital manipulation is closer to painting than photography, but he argues that because of this, digital imagery does not share photographic film's capacity to record, and charges that digitally created imagery transforms reality, rather than representing it. While photography deals with the external, with objective reality, digitally produced images are created internally (17-18). As cinema moves from documentation to simulation, the relationship between spectators and images changes: "the space of CGI is entirely in the realm of simulation; what it manipulates is not profilmic reality itself but rather our consciousness of the relation between an event and its representation" (19). For Groenstad, the digital brings forgery, trickery, distrust and loss of the recording function of photography, and changes the spectator's position in relation to the moving image as one of skepticism.

Whether the change in the status of the image is ontologically and ethically disruptive or simply a novel way to present information that yields similar perceptual clues, the phenomenon undoubtedly changes the ways in which we relate to images, which has further consequences in aesthetics, narrative and many other aspects of film viewing. If we follow Manovich and others in recognizing that the digital media environment foregrounds creative processes and more painterly concerns, we must then think about how this foregrounding manifests in recent films and other media, and what it does to the act of viewing. The change in the ontological status of the image necessarily changes our relationship to all images, and necessitates a rethinking of models of spectatorship.

With the loss of indexicality, any image can realistically represent something that never existed. The image connotes where it used to denote. It suggests where it used to command. Any image can lie on 
levels heretofore unimagined, and the technology for making it do so is widely available, moving beyond the dark room, beyond editorial and compositional discretion and to the level of that which is presented by the image. Representation becomes presentation; reproduction becomes invention.

Once the image is detached from its referent, meaning rests in the mind of the spectator, which is not to say that the spectator independently creates meaning, but the weight of the responsibility for doing so shifts so that meaning-making becomes a negotiation between the critical viewer and the suggestive image. The change in spectatorship that attends the advent of digital media creates a more active spectator, engaged in making meaning and more discerning in image consumption. Technologies such as video games call for a different type of participant, but this mode of spectatorship applies also to traditional films. In a cultural environment where any image can be created to fool the viewer into thinking it is recorded, spectators must either learn to discern the invented from the recorded, or suspect all images, and expect increasing realism from created images. In any case, the spectator becomes much more active in determining the meaning of the image, its reality status, its effectiveness. Every image is in doubt, but the suspension of disbelief still plays a role in creating realistic narrative.

The digital spectator is savvy, discerning, technologically fluent, and, increasingly, also creates and manipulates digital images, still and moving. This latter characteristic affects the relationship between images and viewers in interesting and important ways. With the rise of digital photography, more people are learning that reproduced images, even if automatically or chemically recorded, are manipulable, not static, untouchable records, but images that can be touched up, fixed, distorted, cropped, red-eye removed, and otherwise adjusted. Thus, images are no longer indisputable records of the past, if they ever were. The changed relationship to images comes not from a fundamental change in images-one could always dodge and burn, distort, double-expose and otherwise change a photograph or moving image-but in a popular 
conception of the ease and speed with which these can be changed. The average film viewer is intimately aware that recorded images are what Manovich calls "...raw material for further compositing, animating and morphing. As a result, while retaining visual realism unique to the photographic process, film obtains the plasticity which was previously only possible in painting or animation"("What is Digital Cinema?"). The knowledge of this plasticity lurks behind the willful suspension of narrative and visual disbelief of the film spectator. The Hollywood industry keeps technological wizardry and malleability in the foreground with behind-the-scenes footage of technological advancements, popular 3D animation such as the feature-length films of Pixar and Dreamworks, and DVD extras (which often only reproduce the made-for-TV behind the scenes featurettes).

The result of this is a spectator that understands more about the image-making process, and who demands an increased level of realism, both in spectacle and in invisible manipulation. The oscillation between spectacle and perceptual realism in digital media becomes the norm, where spectators flock to movies that shock them with grand illusions of realism. Bigger, more spectacular special effects integrate seamlessly with photorealistic shots. The awe comes with the perceptual realism. Accordingly, filmmakers alternately showcase new technology with visual extravaganzas and hide the digital magic with touch-ups, corrections, deletions and other embellishments.

This change in spectatorship relies heavily upon the difference in images in the late $20^{\text {th }}$ / early $21^{\text {st }}$ century, when images are as often as not digitally produced and displayed, and when the inherent differences between the digital image and its analog predecessor change our notion of what types of images are possible, and how easily. The presence and possibility of the digital changes our relationship to images as a class of object, which manifests in various ways and these differences constitute sufficient grounds for a radically different type of spectatorship, even in the traditional viewing environment.

On an aesthetic level, one result of this change in spectatorship is a tendency to create worlds that seem to exist more subjectively. This 
occurs in part narratively, with the recent spate of films with unreliable narrators, for example, but also visually, usually through dream sequences, interstitials, title sequences and other non-narrative devices. Sometimes the narrative and the visual come together to create a subjective space that mixes the indexical and the created, the real and the imagined, in more obvious ways.

The merging, or blurring, of the subjective and objective and the desire for mastery and interactivity inherent in the image-manipulation functions of digital media manifest in various ways in moving image technology. In traditional film, they show up in increasingly realistic, fantastic and complex digital special effects, and in display and delivery technologies in theaters. In the home viewing environment, surround sound, widescreen televisions, high-definition video make the experience more theater-like, and DVD technology gives the viewer more control, if they chooses to exercise it.

One film that effectively blurs the boundaries between spectator and film, reality and fantasy, indexicality and special effect is Richard Linklater's Waking Life. This film preserves the indexical nature of predigital film, while using digital technology to create a new image, forcing the spectator to work harder to come to a coherent meaning both of the individual images in the film and the narrative as a whole.

Waking Life was filmed with digital cameras, producing indexical images that were then enhanced, changed, and distorted by digital rotoscoping, or tracing over characters and objects. The effect is a film that plays with our ideas of the cinematic, the real, representation, and perception, to emulate a dream state. The narrative and visual style work together, as the film works in a more associational, seemingly random unless seen as a whole. If the focus of traditional film is the indexical relation to the real, and classical film includes increasing realism, the digital is well suited to the dream, to a more associational and fanciful state, where images are halffound and half-created. In this realm, the task of making meaning falls more to the viewer than ever before. Generally special digital effects range from the utterly realistic, to the cartoonish, sometimes 
invisible to the casual observer and sometimes foregrounded as the main attraction of a film. In the case of rotoscoping, and particularly in Waking Life, the use of the digital remains in the foreground, serving to disorient the viewer and force them to find or make meaning in the unstable, wavy images. Coupled with the subject matter, the technique remains in a middle-ground of representation, between the indexical and the wholly created. What emerges is as close to an expressionistic cinema yet, but with the underlying promise, or threat, of the eruption of the real, of something having really been there, in front of the camera. It is the assumption of indexicality that makes the film hauntingly real, despite its cartoonish look. Through the use of rotoscoping, this film appeals to a pre-rational affective register, inviting the viewer to feel as well as perceive the onscreen images.

The dreamlike quality of the film reveals a function of film alluded to in some spectator theory, but forcibly different here. The film as dream, as pre-perceptual, un-rationally received, subject to unconscious interpretation returns here in a morphed way. Waking Life evokes a dream state, but ultimately asks questions about how to live in waking life. The images stay with the viewer as a lingering feeling; fragmented memories of images remain, as if upon waking from a dream. The difference, of course, is that one can replay the film over and over, each time with the same result onscreen, even if the result is different for the spectator, which leads to the question of replaying, reviewing, rewatching and reperceiving the film. Each viewing will be a little different, although the feeling remains. Of course, this is true of most films, but Waking Life particularly lends itself to reviewing, drawing as it does on more subjective registers. The long descent into a dreamlike state, the dynamic, changing, flowing images, the nearly invisible transitions bring us along like leaves on the surface of a river, occasionally touching the banks, but forever at the whim of the current. Each leaf is carried by the same stream, but ends up in different parts of the river, nearer different banks, spinning and floating in different directions, at different speeds. This film demonstrates the new paradigm of spectatorship in the digital era. 
This film enacts an interactive spectatorship both through its subject matter and visual style. I argue that the visual style of Waking Life is more in line with digital aesthetics and spectatorship than most, or at least that it embodies them more obviously. The intentional mixing of the indexical with the created foregrounds the nature of the digital image, as a hybrid between the two, and forces the viewer into a negotiated position, choosing between meanings, inferring meaning from the visual style as much as through the content of the image and sound. Several factors account for the modified spectator position in this film, which operate on various levels of exhibition. The first level concerns theatrical exhibition, where the film is played onscreen without interruption, whether in a theater or elsewhere, and where the spectator is in a more or less passive position, watching the film unfold as prescribed, with no physical interaction. At this level, the spectator must still choose between meanings, make sense of the images onscreen, decide what is real and what is artificial, and generally perceive the film as presented. The second level is that of the DVD viewer, who can now watch in any order, and with a potential combination of audio and text commentary. These latter features further change the viewing experience with metatextual information that must be processed on different registers, auditorially, and in the case of the text, with frequent pauses to be able to read the text. This creates an entirely new viewing situation, where the viewer is much more critical and attentive, even if the "original" film is obscured by the special features. These two levels of viewing positions are not unique to $W L$, as most films have some level of extra features, usually including audio tracks by filmmakers. This second level comes through more forcefully in this film than in many, however, due to the subject matter and visual nature of the film itself and to the more intrusive characteristics of some of the extras. While this is not entirely unique, it clearly signals the fundamental nature of the digital moving image.

At the level of the image itself, the rotoscoping sometimes serves as an explanatory or illustrative image, and sometimes to obscure or suggest other avenues of thought. In other words, it ranges from more 
concrete to abstract in its relationship both to the underlying image and to the spoken words, which, most of the time, convey the subject matter of the scene.

The "Holy Moment" section of Waking Life illustrates some of the concepts mentioned above concerning both indexicality and distribution and display technologies. During this segment of the film, the main character (Wiley Wiggins) sits alone in a theater and watches two men, Caveh Zahedi and David Jewell, talking onscreen. Zahedi describes Bazin's concept of the holy moment as Jewell more or less passively listens. As he is speaking, Zahedi's hair flows upward and his gesticulating fingers produce tiny sparks and lightning bolts. Occasionally, we get a reaction shot to Wiggins looking slightly amused, or laughing. When Zahedi talks about the frame, he draws a frame with his hands, which then becomes visible and appears to float out to the sides of the screen, reframing the shot, or making the viewer more aware of the frame. After explaining the holy moment, he proposes that they try to create one right there, and the two stare into each other's eyes for several silent seconds. Zahedi's hair continues to flow around as the shot pushes in to close up, and we can see his pupils dilate and compress. Finally, Jewell reflects on the many layers of the experience, the so-called holy moment itself, his awareness of trying to have the holy moment, and so on. At the end of the scene, the background objects fly away and the two characters turn into clouds.

This scene is interesting in part because of its reflexivity. The visual technique of the movie theater, the projector, and the frame emanating from Zahedi's fingers remind the viewer of the materiality of the frame, but the rotoscoping gives Zahedi an ethereal look, not quite grounded in reality, which also reminds the viewer that these images have, of course, been altered. The content of Zahedi's speech also serves to point to the filmmaking process itself, and to this film in particular. He talks about Truffaut's idea that the best films do not always come from the best scripts, and refers to film as being a "slave" to narrative. It is difficult not to draw the connections to this film, with its winding, dreamlike narrative and rotoscoped images, as Zahedi talks about Bazin's notion 
of the holy moment, of capturing reality, and of the relationship between narrative and film. In many ways, this scene offers an analogy between film viewing and the lucid dream state that it tries to depict. A level of awareness and self-reflective consciousness amidst a largely uncontrollable stream of images characterizes both film viewing and lucid dreaming.

The extra features of the DVD, expecially the audio commentary and the text commentary add new dimensions to this experience. The audio commentary includes the director Richard Linklater, the art director Bob Sabiston, main character and animator Wiley Wiggins and producer Tommy Pallotta. At the beginning of the scene, Linklater reveals that he had written a script for this segment full of ideas about narrative of film and other "gibberish," but Zahedi said it sounded too much like Linklater, so Linklater let him improvise, which is what ended up in the final film. This adds to the notion of the film being more than just a script, and the act of listening to the commentary further removes any transparency from the film, as the actual dialogue of the film is difficult to hear, so the viewer gets the meta-information over and instead of the original dialogue.

The text commentary works in a similar fashion, but preserves the sound of the film. The text appears and disappears so quickly at times, however, that the viewer has to pause and sometimes rewind to catch it in its entirety. In this scene, the text commentary describes Bazin's idea of the holy moment, basically expanding on what Zahedi is saying. After a few minutes of no text, the feature reappears near the end, to explain the function of layers on the experience of the holy moment, pointing out the fact that the experienced holy moment also involved a recognition of the experience itself. The near the end of the scene follows, with "/" representing the separation between screens of text:

interesting here is how the 'layers' to which Jewell refers are existent doubly for Waking Life viewers at that moment,/ since the audience is experiencing the Holy Moment and 
reminded that experience itself is a representation/when we see Wiggins watching this film within his own movie house./ So we are watching a film in which Wiggins watches a film in which there's a holy moment that is both enacted and commented upon during its enactment. / And of course there is the question of whether the scene itself derived from a "script" / or improvised and the reenacted for the camera (more layers)....

Taken together, the visual style of the film and the textover suggest that the film viewing experience is much like that of real-world waking perception, with the subject position often transparent but also occasionally obviously foregrounded. At the end of the scene, the text appears with a suggested further-reading list, with three books: Bazin's What is Cinema, Baudrillard's Simulacra, and Robert Stam's SelfReflexivity in Film and Literature, the last of which further reinforces the self-reflexivity of the preceding scene.

Treating the moving image as an indexical sign carries with it some problems, as the link between image and reality is tenuous at best. An image no longer guarantees the existence of the object filmed, but what does it guarantee? If the image is still an index, to what does it point? The concept of the avatar may come into play here. A scale of indexicality, or conformity to visual reality might be useful in determining the effectiveness of an image in convincing the viewer of its reality. Again, some theoretical issues come up, such as, why is this important to spell out? How and why should we talk about the "effectiveness" of the image? What difference does it make that an image is more or less indexical? Realistic moving images still point to something, even if it is not the images depicted. In many science fiction films, for example, the wonder and awe created by digital spectacles serves as much to point to the technology itself, or to the creative hand of the digital artist. In Waking Life, the foregrounding of technological after-effects does the same thing, even while preserving some of the original referent. 
As digital media further infiltrate the image-making process, through increased use of CG and other technologies, the emphasis in moving image studies will shift from the connection between the image and reality, and to that between the image and the viewer/spectator/ player. Emphasis on interfaces, display media, viewing context and the situatedness of the spectator will increasingly figure into the debate about film spectatorship. Meaning is made in an interaction between the spectator and the image, based on visual as well as narrative cues, which increasingly cross cultural boundaries, but which are not immune to the workings of ideology. An updated apparatus theory may be in order, with a spectator that is much less stringently determined, but is more mobile, savvy, self-critical, but still subject to ideological forces, conveyed both within the image and the environment. The ideological effects of the image reside not only in the image, but in the viewing environment and the cultural understanding of the image, which is no longer seen as (primarily) evidentiary, but perhaps more performative, and certainly potentially interactive.

The easy manipulation of images, not just in programs like Photoshop, but in terms of clicking and dragging icons on a computer screen, changing channels on the TV, picture-in-picture, show info overlayed via the cable box, Powerpoint presentations, ATM interactions, self checkout lanes at the grocery store, and the myriad other technologies we face on a daily basis, change our relationship to images, to where the interaction is more or less complex depending on the medium, but the possibility is always present. While film viewing seems to be the least interactive experience modern people experience, this is offset by consumer demands of cutting edge technology, bigger and louder films, and more CG. The interactivity we see in other realms transfers to the film as we help make meaning in the theater (Burnett), but gets more complex and stronger when the film comes to DVD.

In order to understand the shift in moving image technology that accompanies the move to digital media, media studies need to account for the perception of images across media and viewing environments and distinguish this from viewing images in the "real world". Theories 
of affect and cognition, coupled with close analysis of aesthetic and technical qualities of various media artifacts will yield a more comprehensive framework within which scholars can understand the shifting ground upon which the field rests. By recognizing that the comprehension of moving images is itself virtual, contingent and interactive, we can begin to understand the phenomenon of media viewership as something that is both culturally contingent and innate, conditioned in part by ideological forces, but also in part prior to them. Content and technology, narrative and form are inextricably linked, but partially independent, as nodes in a network that depend on each other for communication, that exist in relation to each other, but which still have certain sovereign qualities. A systematic study of the various media as they relate to each other, both in content and form, will produce a textured field of study that emphasizes the viewer/spectator/ participant not as a predetermined, empty field, but as an active participant that brings a subjective perspective to the experience. Somewhere between the empty, fixed viewer, and the enigmatic, unpredictable subject lies the postmodern spectator, conditioned by political, ideological forces, positioned by the media, but also producer of it, producer of meaning within it, perhaps not by analysis, but by use of it. In the end, the user combines, assembles, collects and changes media artifacts, and meaning is produced in the interaction between the user and the image.

The shift from indexicality, where the image bears a causal relation to the phenomenon, to that of subjective interactivity underlies the perception of images as created, rather than recorded. This shift opens up the field of the moving image to different types of interpretation and use, and significantly changes the position of the image consumer/ producer (the term "prosumer" is a contraction of professional and consumer, referring to video equipment that is professional grade, but consumer-priced. It could just as well be a contraction of "producer" and "consumer"). It also dramatically changes the concept of realism. Prince's concept of "perceptual realism" works for films that attempt a type of realism that corresponds to an objective reality, but for films 
like Waking Life that present a different version of reality that is far more subjective, it falls short. Perceptual realism works with digital special effects, and I suspect it works with realistic videogames, but a continuum of realism would be more appropriate for genres or films where the abstract or subjective take precedence. As Waking Life shows, digital effects can be used not only for perceptually real special effects, but also to blur the line between the real and the illusory, between realism and the fantastic, thus shifting the weight of signification to the viewer. A subjective realism that takes into account diverse viewing environments as well as changing aesthetics would unite discourses of spectatorship and realism in useful ways.

\section{References}

Bazin, André. What Is Cinema?Trans. Hugh Gray. Ed. Hugh Gray. Berkeley;: University of California Press, 1967. 2 vols.

Burnett, Ron. How Images Think. Cambridge, Mass. : MIT Press, 2004.

Groenstad, Asbjoern. "Back to Bazin? Filmicity in the Age of the Digital Image." Popular Culture Review 13.2 (2002): 11-23.

Manovich, Lev. "What is Digital Cinema?" Retrieved September 20, 2005, from http:/ /www.manovich.net/TEXT/digital-cinema.html.

Prince, Stephen. “The Discourse of Pictures: Iconicity and Film Studies." Film Quarterly 47.1 (1993): 16-28. 